\title{
Professional Skills Development Through the Network Learning Community Using an Online Learning Platform
}

\author{
https://doi.org/10.3991/ijim.v15i12.21587 \\ Muhammad Ashar ${ }^{\bowtie}$, Waras Kamdi, Dediek Tri Kurniawan \\ Universitas Negeri Malang, Malang, Indonesia \\ muhammad.ashar.fteum.ac.id
}

\begin{abstract}
Networked learning Community (NLC) that integrates a professional context into the learning experience that uses learning networks to promote self-efficacy and skill to learn. There are three ways for teaching integrate in online learning. Firstly, personal learning networks to focusing of activities, secondly, live streaming and online based learning communities. Finally, immersive skills and experience mastery for expert. Based on the hypotheses of the NLC thinking on online learning service users, it can help self-development skillfully and with high self-confidence in using a personalized learning platform. Meanwhile networking for learning with professionals will strengthen. Influence on skills and experiences on self-achievement through learning experiences that are suitable for oneself and then become professionals through learning in today's digital era. An NLC that follows the pattern and mission of 21st century learning is the way to go for scaling up efforts to redesign academies that offer skills with a forum for broad but personal learning. The live streaming technique in the learning process in online media has a significant impact in monitoring and monitoring one-on-one learners' abilities. Learning outcomes can be easily corrected and evaluated by relevant experts so that the work can be used as a good portfolio. In the application of the NLC the target output is that there is a promotion mechanism for students to the industrial world by bringing together professional companies and / or developing entrepreneurship with the addition of business training to the relevant NLC. The results of the platform development show that the flow and process of improving skills and professional learning with the community in one field of multimedia industry is getting better.
\end{abstract}

Keywords - Networked Learning Community, 21st century learning, multimedia industry, live streaming media

\section{$1 \quad$ Introduction}

Education is one indicator of the development of a country's civilization. Through education, human beings will continue to develop in accordance with the demands of the global world, with education the windows of the world will be opened so that it 
will be clear that in the world all knowledge will be revealed in a real way. However, in reality education in Indonesia still needs to be improved, especially in learning in the era of networked learning. Learning that should be focused on the speed of understanding the concept optimally in a short time with interactive digital content online and live streaming. Modeling of the principles of networked learning (networked learning community) who get opportunities for learning opportunities and receive analytical feedback on work assignments at.

Dimension of the networked learning model is the relationship between the three knowledge areas: (1) Practitioners of knowledge of what others understand in the online learning process on the platform used, (2) theoretically available public knowledge from existing research to be included in the online learning environment); (3) New knowledge that can be created collaboratively and well monitored. Through network-based activities and classroom use [21] state in their recent publication on "Connecting school knowledge and university knowledge, they (networks) find a way for human knowledge (knowledge created by lecturers on assignments) to informing outside knowledge "(the knowledge of researchers and policy makers), and vice versa. Meanwhile, [4] are consistent with the challenges of an increasingly knowledge-based era, which triggers new ways of learning that involve leveraging multiple perspectives into shared group or group intelligence and integrating new theories, competencies, capacities and practices with each other.

The view of learning in a networked learning community although there is nothing new about the network of lecturers or teachers, university leaders or school principals, and campuses or schools have long been involved with each other in the form of collaborative activities. However, there is something fundamentally more purposeful and aspirational about the notion of "collaborative capacity", as it is considered part of the future innovation, development and knowledge management architecture of systems on campus or school.

The Networked Learning Communities program in the UK is a large-scale development and inquiry initiative involving 137 networks (1,500 schools) between 2002 and 2006. It is specifically designed to provide policy and learning systems (practices) on network design and implementation, facilitation and leadership issues, system support, and incentives. Evidence results on how and under what conditions networks can contribute to improving student achievement on leadership practices that prove to be the strongest potential school-to-school learning and about the emerging new relationships between networks as engagement units and Local Authority partners.

The development of networked learning with a community of users who simultaneously responds to online learning and live streaming is used on the academy platform in the multimedia industry field with education towards work professionals in industry or companies through link and match and business through sharing content with a Stratup model. The development of the platform is mainly designed by means of a Smart Learning Management System by testing the usability of the system and the feasibility of users with an intermediate level, while tutors are selected with high professional skills (advanced). System policies using AI algorithms place priority automatically on the results of learning reviews and evaluations through points of interest (POI) by clustering users into two professional groups (high skills for industry and good skills for business) [18]. 
In the field of study, improving Networked Learning Communities with an open platform to recruit professional workers supported by a live streaming and online learning NLC platform using the design thinking method testing and the User Acceptance Test model in testing the feasibility of this NLC application in order to find out what potential users are interested in. and other visitors to take advantage of the features as a potential for increasing understanding of the concepts on the courses offered [22].

The research contribution is expected that the results of this research can be used as research products implemented on the new NLC platform, the development of this platform in various campuses, cities and regions that have adequate ICT facilities and infrastructure.

\section{$2 \quad$ Literature Review}

Model for networked learning [12] as a way of accessing and describing the characteristic components of network activity. Learning network with architecture as in the following image:

Collaborative groups to work and learn together engage in contributions with a common goal. This joint activity provides focus, strength and purpose to the network. Here are six strands of the basic framework for a networked learning community design:

a) Student learning - Pedagogical focus

b) Adult learning - A major aspiration professional learning community

c) Leadership learning - At all levels

d) Organizational learning - The new organizational learning norm

e) School- learning to school - Network learning

f) Network-to-network learning - Lateral systems learning

Each network is also chosen to have at least one external partner. One for collaboration is: working smarter together, rather than working harder alone and for a critical moral purpose and community dimension: learning from, with and on behalf of one another.

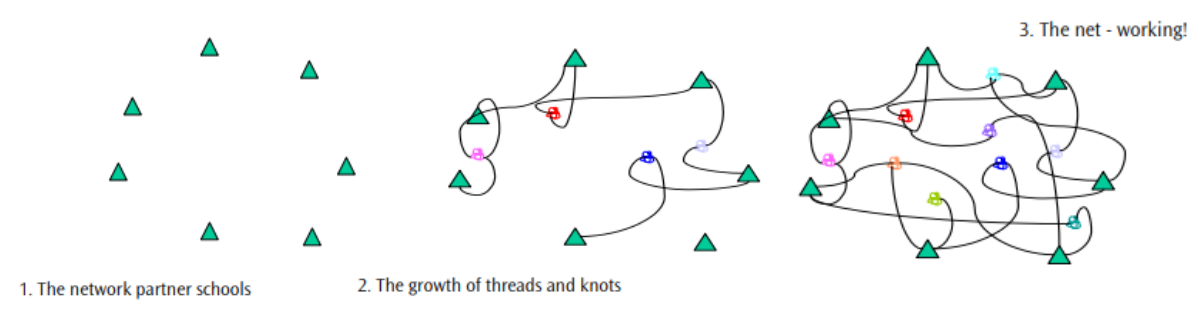

Fig. 1. Model NLC path

The use of social media, blogs, and learning communities including of networked learning that offer different prices to support self-efficacy development. However, it is necessary to review the applications of networked learning, which integrates pro- 
fessional contexts into the academic learning experience. Interventions that use learning networks to promote professional training and social networking for students' selfefficacy.

There are three techniques in integrating learning design: First, helping students to develop personal learning networks. Second, using blog-based learning as a media in teaching. The last, to sharpen teachers' networking skills with professionals. Based on the assumption, networked learning will help to support a gradual buildup of confidence and skills in an online learning community among coordinators, whereas to learn for networking with experts will give a lot of impact in mastery on the progress of students. A survey of undergraduate students in the School of Business, there are 75 students found the result of the intervention in significant gains in self-confident for professional training and social networking. In the coming years, there were reports of high likelihood users engaging in this activity. Finally, the learning experiences they acquire are quite relevant in their lifelong learning and professional success based on the students' perception.

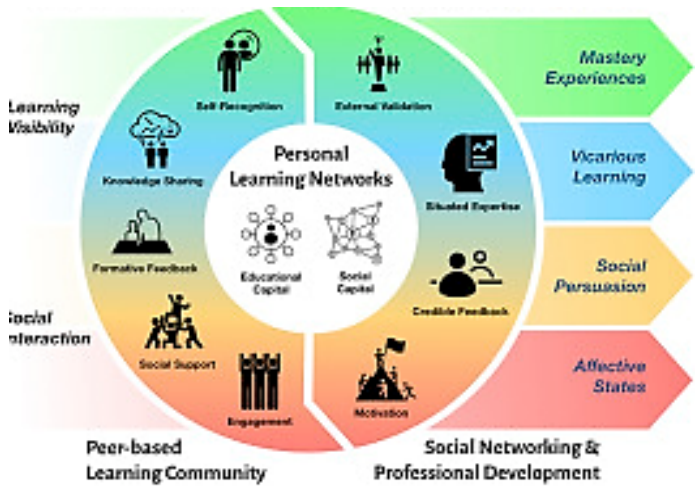

Fig. 2. Model NLC self-efficacy

Creating new opportunities to share and improve skills by collaborating with others school to strengthen professional learning by Networked learning communities or NLCs [7]. When it comes to changing schools, educators should consider tapping into the power of Network Learning Communities. The aim of education in 21 st century with Networks aligned is an important mechanism to increase efforts to redesign the school by offering a broad forum but personal leraning. Reflectivity in research practice, collabotive learning, co-ownership, partnerships, teacher empowerment, and school leadership. Carefully designed networks serve as breeding grounds for innovation and risk-taking, building better capacity for reform to encourage a lot of ideas that exist in the movement of school redesign, which facilitates a more dynamis and interactive level of collaboration and providing opportunities for teachers to create knowledge Traditional cross-border enhances teacher practice in a wide enough ideas to use and engage the participants of joint problem solving enabled some schools to share expertise with a wider audience promoting challenging ideas rather than prescribing allowing for discussion of ideas without agreed solutions respecting and encouraging teacher knowledge within and beyond expert knowledge to create 
new knowledge overcoming traditional isolation and hierarchical models fostering higher quality professional learning experiences.

A strong network shares the following characteristics: clear goal and direction of collaboration and commitment built on purpose adequate resources emphasis on building relationships through meaningful activities view network leadership as a cross-cultural resource intermediary We have experiences and expertise in creating, facilitating, and growing a networked learning community that can help design and strengthen communities from scratch. In this developed country, some previous surveys and research found that around $95 \%$ of students owned smart mobile devices in Universities. Proposing an operational framework for designing Mobile Collaborative Informal learning activities using SMDs. Result show that experiments and case studies conducted to study Informal Mobile Collaborative learning using Activity. [17]. An online learning environment in the form of a "community of inquiry" was developed by [8] There are three distinct elements to this "presences", namely: teaching, cognitive, and social. (see Figure 3) While recognizing the relationships and overlap among all three components [4] each component is recommended for further research. [15].

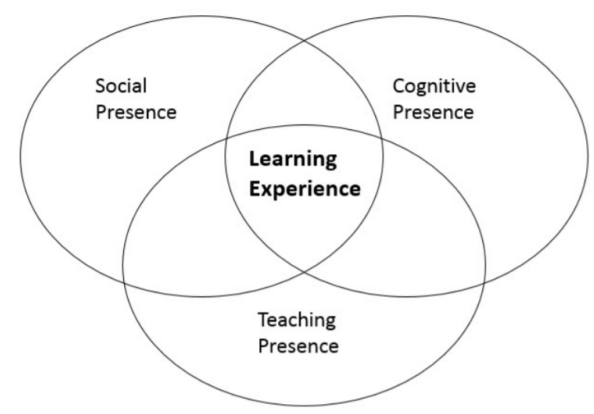

Fig. 3. Community of Inquiry

\section{Method}

The ways and steps that can be taken in the learning process in the 21 st century education era are "Design Thinking" with a human-oriented approach in determining short-term and long-term strategies. This method in education is called "Design Thinking for Educators". There are three components the learning process of design thinking: First, an approach and mindset to learning. Second, creative problem solving. And the last, collaboration. In practice, a structured framework in design process is broken up into five stages: identify challenges, gather information, generate potential solution, and test solution.

Design Thinking can be used to any field through the creation of a learning project that can be designed in a learning activity system as an innovative learning process. Tutors guide the younger generation to undertake new professions that do not currently exist. In addition, the design thinking process will assist tutors in conducting mentoring to face future professional challenges through the concept of a networked learning community. 
In the application of design thinking in the prospect of NLC studies by using online courses based on live streaming platforms, this can use the practical high competence method for personalized learning and efficacy improvement. The stages are as follows:

1. Discovery: Understanding and researching problems that have been prepared by the teacher or rather the teacher provides challenges to students in the form of a problem. Students are assisted by the teacher to jointly understand and examine the problems that have been provided by the teacher in accordance with the material they are going to learn. Students are asked to understand and research the problems given through existing material sources, either through textbooks, the internet or other sources so that students do not only receive information from one source and the knowledge of students will be wider.

2. Interpretation: Connecting problem points in the research. The teacher directs students to connect all the problems they find so that the problem will be conical to make it easier to arrange the stages of solving the problems that have been previously given.

3. Ideation: Generate and refine ideas on how to solve problems. Students are stimulated to look for or explore new ideas in solving problems they find and the teacher has the task of directing students so that students are able to issue their creative ideas but in accordance with the corridors of existing problems.

4. Experimentation: Testing students' ideas, collaborating with others, getting feedback. Students do experiments / experiments to test their ideas, in doing this step it is expected that students collaborate with each other so that communication between them can run well. In this stage the teacher is tasked with providing feedback on the experiments that students make so that they can be more focused and students get input in developing the experiments they are doing.

5. Evolution: Draw conclusions and develop students' ideas. At this stage students will draw conclusions from all the stages they have done and at this stage students are also expected to be able to present the new ideas they have gotten to their colleagues so that in class there will be some new ideas that students will develop or develop. looking for new inspirations in solving the problems they find.

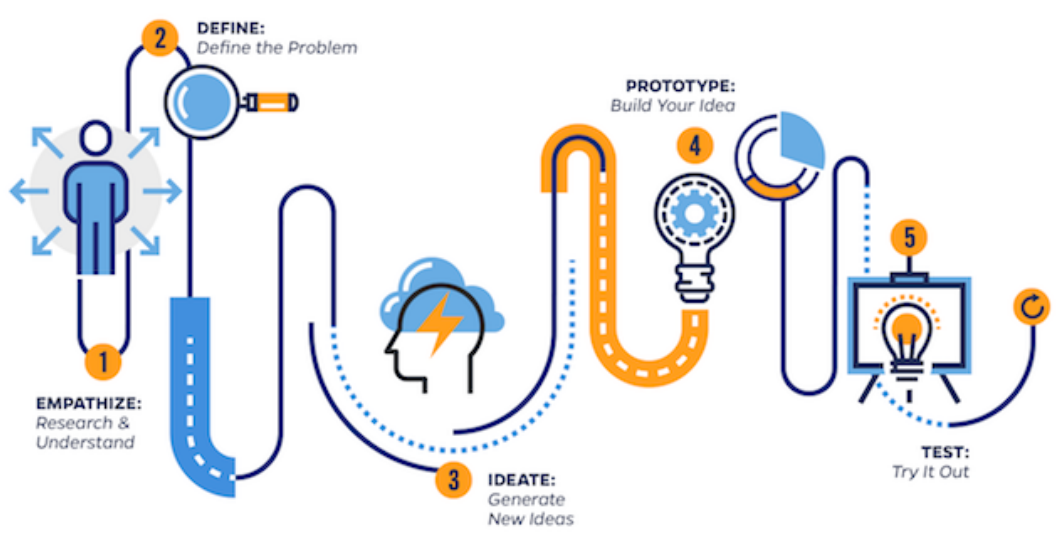

Fig. 4. Design Thinking Process for Educator Scheme 


\section{$4 \quad$ Results and Discussion}

\subsection{Learning evaluation results with the NLC platform}

Using a platform by applying practical learning to the community through live streaming-based professional mentors has the potential for self-development at a good average. The following can be seen in Figure 4.1 which shows the evaluation process and the average learning outcomes (Learning Community Group).

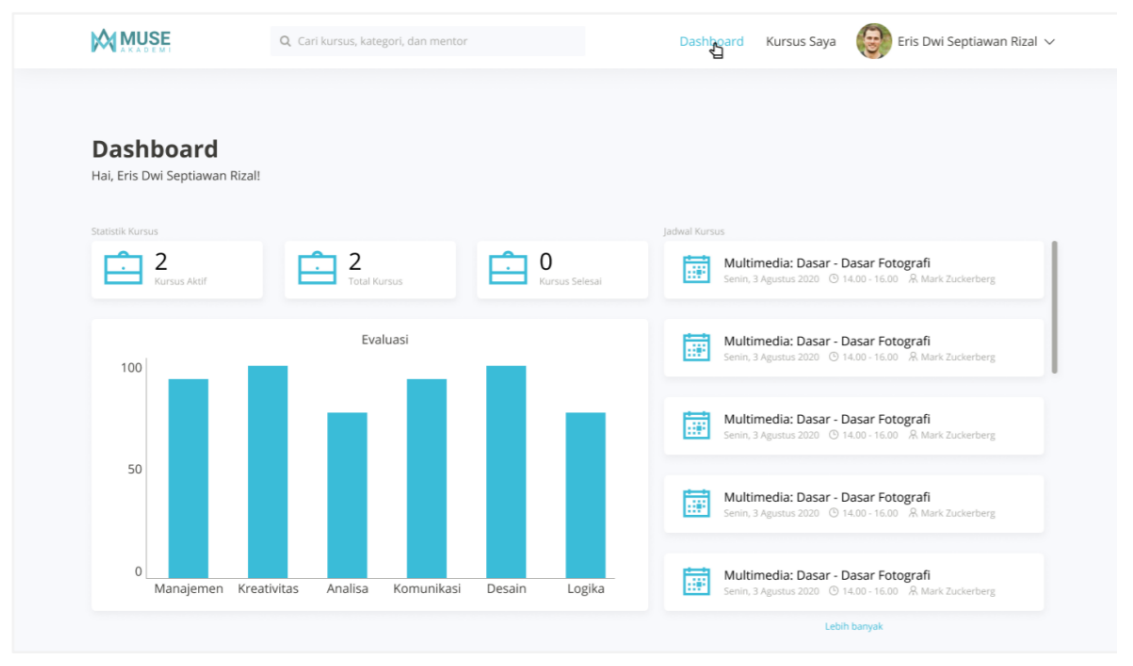

Fig. 5. Evaluation process and the average learning outcomes

For a number of Photography community users (20 students) carried out a learning scenario in 3 steps: Theory, Practice and Feedback) by means of a 14 day live stream) the resulting learning evaluation is as follows:

Table 1. Learning Evaluation Results

\begin{tabular}{|l|c|c|c|}
\hline \multicolumn{1}{|c|}{ User Interaction } & Potential Self & Pre-Test & Pos-Test \\
\hline 20 users of the homogeneous community live streaming & 89 & 78 & 92 \\
\hline 20 users of online homogeneous communities & 84 & 83 & 89 \\
\hline 20 users of heterogeneous community live streaming & 90 & 84 & 91 \\
\hline 20 users of heterogeneous communities online & 86 & 80 & 87 \\
\hline
\end{tabular}

Self-potential values include management, creativity, analysis, communication, design, and logic of thinking). From the results of the assessment of product work in learning scenarios using live streaming and online, it is obtained a different pattern of potential for each user. The following is a chart of the results of self-potential with photographic products in each user group, a homogeneous community (20 users with communities in the multimedia field) and heterogeneous communities (20 users with mixed communities, IT, Multimedia, Art and Design). 


\section{Conclusion}

The development of the NLC system with live streaming-based online training can improve user skills in a community with an open and adaptive teaching system.

The learning process with visualization and media interaction as well as the ability of the community to understand the concepts and material on a level will reinforce one another by sharing in the forum feature or direct discussion on the chat available with live streaming.

\section{References}

[1] Allen, K.E. \& Cherrey, C. (2000) Systemic Leadership: Enriching the Meaning of Our Work, University Press of America, Boston, Maryland.

[2] Bentley, T. Crane, H. Horne, M. Stasinopoulou, K. and Skidmore, P. (2002). Learning the Lessons: How past policy initiatives can help practitioners in the Networked Learning Communities programme, Demos, NCSL commissioned research paper.

[3] Bentley, T. (2003). The purposes of networks and their contribution to collaborative capacity, unpublished policy discussion paper, Demos, London.

[4] Bush, T. and Jackson, D. (2001) Preparation for school Leadership: International Perspectives, paper presented at the University Council for Educational Administration Annual Conference, Cincinnati, USA, November 2001.

[5] Bryk, A. Camburn, E. \& Louise, K.S. (1999). "Professional Community in Chicago Elementary Schools: Facilitating factors and organisational consequences", Educational Administration Quarterly, 35 (suppl), 751-781. https://doi.org/10.1177/0013161x99355004

[6] Canter, Rosabeth Moss, (1994) "Collaborative Advantage: the Art of Alliances", Harvard Business Review, July Aug., 1994, 96-108.

[7] Castells, Manuel (2000) Toward a Sociology of the Network Society Contemporary Sociology, Vol 29 (5) p693-699.

[8] CERI/OECD (2000) Schooling for Tomorrow: Innovation and Networks, Portuguese Seminar, Lisbon, 14th - 15 ${ }^{\text {th }}$ September 2000 Rapporteurs Report (David Hopkins).

[9] Creasy, J. and Cotton, C. (2004) New Visions: Meaningful leadership learning, paper prepared for ICSEI, 'Building Bridges for Sustainable School Improvement', January 2004, Rotterdam.

[10] Church, M., Bitel, M., Armstrong, K., Fernando, P., Gould, H., Joss, S., MarwahaDiedrich, M., De La Torre, A-L. and Vouhe, C. (2002). Participation, Relationships and Dynamic Change: New Thinking on Evaluating the Work of International Networks. London: University College London.

[11] CUREE [the Centre for the Use of Research and Evidence in Education] (2003), Early Messages from the Networked Learning Communities: some implications for policy, September 2003

[12] Demos/NCSL (2002) Learning from Experience: A literature review designed to help those establishing and running Networked Learning Communities, paper presented at the Networked Learning Communities Launch Conference, June 2002.

[13] Dudley, P; Hadfield, M: and Carter, K. (2003) Towards Knowledge-Based Networked Learning: what we have learned from the first Networked Learning Communities Programme Enquiry, Summer 2003. NCSL.

[14] Fielding, M. and Webber, T. (2003) Action Learning: Tackling practical challenges, an NCSL commissioned research report. 
[15] Garrison, D.R. \& Shale, D. (1990). Education at a distance: From issues to practice. Malabar: FL: Robert E. Krieger.

[16] Fukuyama, F. (1995) Trust: The Social Virtues and the Creation of Prosperity, Free Press.

[17] Granovetter, M. (1973), The Strength of Weak Ties, American Journal of Sociology, 78 (6): 1360-1380. https://doi.org/10.1086/225469

[18] Hasnain Zafar Baloch, Azizah Abdul Rahman, Noorminshah A Ihad,(2012) Mobile Collaborative Informal Learning Design: Study of collaborative effectiveness using Activity Theory, iJIM, Vol 6 No 3. https://doi.org/10.3991/ijim.v6i3.2090

[19] Kahne, J. O Brien, J. Brown, A. \& Quinn, T. (2001). Leverage, Social Capital and School Improvement: The case of a school network and a comprehensive community initiative. Educational Administration Quarterly, 37(4), 429-461. https://doi.org/10.1177/0013 $\underline{1610121969389}$

[20] Kerr, D. Aiston, S. White, K. Holland, M. and Grayson, H. (2003) Literature Review of Networked Learning Communities, NFER, NCSL commissioned research.

[21] Lieberman, A., \& McLaughlin, M.W. (1992). Networks for Educational Change: Powerful and problematic. Phi Delta Kappan, 73(9), 673-677.

[22] T. Monahan, M. Bertolotto and G. McArdle (2019). Usability Testing of a Collaborative and Interactive University on a Mobile Device. iJIM - Volume 3, Issue 4, October 2009. https://doi.org/10.3991/ijim.v3i4.905

\section{$7 \quad$ Authors}

Muhammad Ashar is a Lecturer at the Electrical Engineering Department, Faculty of Engineering, Universitas Negeri Malang.

Waras Kamdi is a Professor of Mechanical Engineering Learning Technology, Faculty of Engineering, Universitas Negeri Malang.

Dediek Tri Kurniawan is a Lecturer at the Management Department, Faculty of Business Economics, Universitas Negeri Malang.

Article submitted 2021-01-28. Resubmitted 2021-02-12. Final acceptance 2021-04-19. Final version published as submitted by the authors. 